\title{
PROPAGAÇÃO VEGETATIVA DE CEDRO-AUSTRALIANO (Toona ciliata M. Roemer) POR MINIESTAQUIA ${ }^{1}$
}

Jonicélia Cristina Araújo Vieira de Souza ${ }^{2}$, Deborah Guerra Barroso ${ }^{3}$, José Geraldo de Araújo Carneiro ${ }^{3}$, Silvio Lopes Teixeira ${ }^{3}$ Ernando Balbinot ${ }^{2}$

\begin{abstract}
RESUMO - O método de propagação usual do cedro-australiano (Toona ciliata) é via seminal, entretanto a oferta sazonal das sementes e sua curta viabilidade ao longo do tempo representam um problema para a produção contínua de mudas destinadas à implantação de povoamentos. Este trabalho foi conduzido com o objetivo de avaliar a viabilidade da propagação vegetativa da espécie por miniestaquia e a necessidade da aplicação de acido indolbutírico (AIB) para o enraizamento das miniestacas. A partir de um banco de estacas de origem seminal, foram obtidas brotações para produção de mudas clonais, em três diferentes épocas de coleta (2,5; 4,5; e 5,5 meses após a recepa das mudas). Antes do estaqueamento, as miniestacas tiveram suas bases imersas em quatro concentrações de AIB $\left(0 ; 1.500 ; 3.000 ;\right.$ e $\left.4.500 \mathrm{mg} \mathrm{L}^{-1}\right)$. Durante o experimento, obtiveram-se $100 \%$ de sobrevivência das minicepas e das miniestacas. Houve $100 \%$ de enraizamento das miniestacas nas três coletas, não ocorrendo diferença no comprimento de raízes em função das doses de auxina aplicadas. Quanto maior o intervalo entre as coletas e quanto maiores as brotações que originaram as miniestacas, maior a velocidade de crescimento das mudas. Miniestacas de cedro-australiano possuem capacidade de enraizamento, e mudas recepadas apresentam brotação, possibilitando a clonagem da espécie pelo processo de miniestaquia.
\end{abstract}

Palavras-chave: Ácido indolbutírico, cedro-australiano e silvicultura clonal.

\section{VEGETATIVE PROPAGATION OF Toona ciliata M. Roemer BY THE MINICUTTING TECHNIQUE}

\begin{abstract}
Sexual propagation is the method commonly used for the Australian Red Cedar Toona ciliata. However, seasonal seed availability and short viability are a concern for the continuous offer of seeds for implantation. The objectives of this study were to evaluate the viability of vegetative propagation of this species through minicutting and to test indolbutiric acid (IBA) application for rooting of minicuttings. Sprouts for clonal minicutting production were obtained from a miniclonal garden established from seeds, in three different harvest times (2.5; 4.5 and 5.5 months after seedling cut). Before staking, the minicutting base was immerged at four IBA concentrations $(0 ; 1500 ; 3000$ and $4500 \mathrm{mg} \mathrm{L-1})$. Minicutting survival and rooting rate were $100 \%$ in the three harvesting dates, without quantitative differences between root lengths by auxin dose application. The longer the time interval between the two minicutting production harvests, the greater the speed of minicutting growth was. Australian Red Cedar minicuttings have a high rooting capacity and the cut seedlings present sprout production, , allowing cloning by the minicutting technique.
\end{abstract}

Keywords: Indolbultiric acid, Australian Red Cedar,and clonal silviculture.

\footnotetext{
${ }^{1}$ Recebido em 04.09.2007 e aceito para publicação em 06.03.2009.

${ }^{2}$ Doutoranda CONICET - Universidad Nacional del Litoral. E-mail: <agrisilver@ gmail.com>.

${ }^{3}$ Universidade Estadual do Norte Fluminense (UENF), Campos dos Goytacazes-RJ.E-mail: <deborah@uenf.br>; <carneiro@uenf.br>.
} 


\section{INTRODUÇÃO}

Entre as espécies que vêm sendo plantadas visando à produção de madeira para serraria está o cedroaustraliano (Toona ciliata M. Roemer), espécie da família Meliaceae, cuja origem se estende desde a Índia e Malásia até o norte da Austrália. A espécie possui similaridade botânica com os cedros nativos do gênero Cedrella da Mata Atlântica e o mogno (Swietenia macrophilla King) da Floresta Amazônica (LORENZI et al., 2003; PINHEIRO et al., 2003).

Essa espécie achou no Brasil condições favoráveis ao seu crescimento e possui resistência contra à broca da gema apical (Hypsipyla grandella), que ataca outras meliáceas e é encontrada na América, (OIANO, 2000; CASTRO-GAMBOA, 2000). Porém, o cedro-australiano é também atacado pela Hypsipyla robusta, praga florestal que não tem ocorrência natural na América (CUNNINGHAM et al., 2005).

Hoje, o processo de propagação comercial do cedroaustraliano é exclusivamente por sementes (LORENZI et al., 2003; PINHEIRO et al., 2003). Entretanto, fatores como a oferta sazonal de sementes, a curta viabilidade destas (SCOCCHI et al., 2006) e, especialmente, a grande variabilidade dos povoamentos implantados no país, com manifestação de características genéticas indesejáveis, justificam a necessidade do início de um processo de melhoramento da espécie, bem com do uso da propagação vegetativa para a implantação contínua e homogênea de povoamentos comerciais.

As principais empresas florestais brasileiras vêm usando amplamente a propagação vegetativa por miniestaquia para a produção comercial de mudas, o que consiste na utilização de brotações novas, coletadas em mudas propagadas vegetativamente e conduzidas em minijardim clonal (TEIXEIRA, 2001).

A utilização dessa técnica tem possibilitado o rejuvenescimento de alguns materiais suficiente para eliminar a utilização de reguladores de crescimento e reduzir a variabilidade durante a multiplicação (HIGASHI et al., 2000; TITON et al., 2002).

A utilização da propagação vegetativa de espécies florestais, associada a programas de melhoramento, tem como finalidades acelerar o crescimento, aumentar a produtividade e gerar madeira de qualidade e homogênea (ALFENAS et al., 2004), pela multiplicação de plantas selecionadas.

R. Árvore, Viçosa-MG, v.33, n.2, p.205-213, 2009

\section{R. Árvore, Viçosa-MG, v.33, n.2, p.205-213, 2009}

Com a propagação vegetativa, espera-se contornar os problemas inerentes à multiplicação seminal do cedroaustraliano, garantir a produção durante todo o ano e permitir rápida seleção e multiplicação de indivíduos superiores, tornando os plantios mais produtivos e uniformes.

Para a adoção do processo de miniestaquia na propagação comercial do cedro-australiano são necessárias, entretanto, informações sobre a produtividade e longevidade das minicepas em sucessivas coletas e, quanto às miniestacas, sobre a relação à capacidade de enraizamento, ao estabelecimento e à influência da época de produção e intervalos de coleta sobre elas.

Este trabalho teve como objetivo verificar a viabilidade da técnica de miniestaquia como método de propagação vegetativa do cedro-australiano. Para isso foram avaliados: a produção e sobrevivência das minicepas em sucessivas coletas; a capacidade de enraizamento das miniestacas em diferentes coletas e a necessidade de reguladores de crescimento; e o crescimento das miniestacas, originadas de coletas sucessivas.

\section{MATERIAL E MÉTODOS}

\subsection{Implantação e avaliação do banco de estacas}

A implantação do minijardim clonal foi conduzida em casa de vegetação coberta com plástico (polipropileno 150 micra) e sombrite (30\%), no Centro de Ciências e Tecnologias Agropecuárias da Universidade Estadual do Norte Fluminense, em Campos dos Goytacazes, RJ.

Mudas de cedro-australiano foram produzidas por via seminal, em tubetes plásticos de $280 \mathrm{~cm}^{3}$, em substrato comercial Multiplant Florestal®, fertilizado com adubo de liberação lenta, Osmocot ${ }^{\circledR}$ de formulação N-P-K 14-14-14 (em 225 g por saco de substrato (25 kg).

Aos 90 dias após a semeadura, quando as mudas estavam com aproximadamente $15 \mathrm{~cm}$ de altura, foi efetuada a poda da parte aérea, a cerca de $6 \mathrm{~cm} \mathrm{da}$ base, e posteriormente pinceladas, na região de corte, com solução de fungicida sistêmico Manzat® 500 (Mancozeb), 0,5 $\mathrm{g} \mathrm{L}^{-1}$. Com isso, foram obtidas 300 minicepas, para posterior fornecimento de miniestacas para a produção de mudas. 
Foram constituídas 10 parcelas compostas por 30 minicepas, dispostas aleatoriamente para avaliação das brotações ao longo do tempo (10, 18 e 22 semanas após o corte para implantação do minijardim).

As épocas das avaliações foram determinadas em função da existência de brotações em tamanho mínimo para a confecção de miniestacas. Nas diferentes épocas, retirou-se de cada minicepa uma miniestaca da brotação mais desenvolvida para a produção de mudas, sendo medidos o diâmetro das minicepas e o diâmetro e altura das brotações e contado o número acumulado de brotações.

As minicepas foram mantidas, até a primeira coleta, em uma densidade de 225 mudas $\mathrm{m}^{2}$, e após essa coleta, dispostas em espaçamento maior, resultando em 112 mudas $/ \mathrm{m}^{2}$.

As minicepas foram identificadas individualmente, assim como as miniestacas delas originadas. A identificação foi realizada em todas as miniestacas, nas três diferentes épocas, para posterior correlação entre os dados.

Os dados relativos às minicepas foram submetidos à análise de variância e as médias, comparadas pelo de teste de Tukey (5\%).

\subsection{Miniestaquia}

No segundo ensaio, cujo objetivo foi testar a viabilidade de produção de mudas de cedro-australiano pelo processo de miniestaquia, com ou sem aplicação de auxina, imediatamente depois de coletadas as miniestacas apicais foram preparadas com tamanho de 4 a $6 \mathrm{~cm}$ e 2 folhas, cortadas em $50 \%$ de sua área, para diminuir a transpiração. Antes do estaqueamento, as miniestacas foram submetidas aos tratamentos aplicados, por via líquida, na base da miniestaca, durante 15 segundos.

Como tratamentos, foram testadas quatro doses de ácido indolbutírico (AIB): 0; 1.500; 3.000; e 4.500 $\mathrm{mg} \mathrm{L}^{-1}$ em três épocas de coleta: 10,18 e 22 semanas após o corte das matrizes (recepa). Em cada época, os tratamentos foram dispostos em blocos casualizados, com 15 mudas por parcela.

No preparo das soluções de AIB para tratamento das miniestacas foi utilizado hidróxido de sódio $(\mathrm{NaOH}$ $1 \mathrm{~mol} \mathrm{~L}^{-1}$ ), para diluir a auxina.
Para a produção das mudas clonais foi realizado o estaqueamento das miniestacas em tubetes plásticos de $110 \mathrm{~cm}^{3}$, com o mesmo substrato e adubação utilizados para a produção das minicepas. Após o estaqueamento, os tubetes foram transferidos para casa de vegetação com sistema de nebulização intermitente, mantendo elevada umidade relativa do ar necessária para evitar o ressecamento das folhas (80 a $100 \%)$ e temperatura média de $27^{\circ} \mathrm{C}$.

As miniestacas permaneceram sob nebulização por 40 dias. Procedeu-se, após esse período, à avaliação das mudas clonais, derivadas das miniestacas, quanto à sobrevivência, porcentagem de estacas enraizadas, crescimento em altura e diâmetro do colo, biomassa de parte aérea e comprimento e diâmetro de raízes.

Cinco mudas clonais, das 15 mudas de cada tratamento, tiveram suas raízes lavadas sobre peneiras, para determinação do comprimento e diâmetro das raízes adventícias produzidas por miniestaca, o que foi avaliado por meio da digitalização de imagens, segundo Freitas et al. (2005).

Em 10 mudas de cada parcela foi determinada a matéria seca da parte aérea. Após a separação das raízes, esse material foi colocado em estufa de circulação forçada a $70{ }^{\circ} \mathrm{C}$, por $48 \mathrm{~h}$, para posterior pesagem.

Os dados foram submetidos à análise conjunta de experimentos e as diferenças detectadas, comparadas pelo teste de Tukey a $5 \%$ de probabilidade e ajustes de regressão (PIMENTELGOMES e GARCIA, 2002).

\section{RESULTADOS E DISCUSSÃO}

\subsection{Avaliação do Banco de Estacas}

Durante o experimento foram obtidos $100 \%$ de sobrevivência das minicepas, após as três coletas sucessivas de estacas.

O número médio de brotações das 300 minicepas avaliadas neste trabalho, após a recepa das mudas para implantação do minijardim, encontra-se na Tabela 1 , sendo esses dados acumulativos, em cada coleta. Após a primeira coleta, com a quebra da dominância houve estímulo à brotação das minicepas, entretanto a espécie apresentou sempre dominância de uma brotação sobre as demais.

R. Árvore, Viçosa-MG, v.33, n.2, p.205-213, 2009 
Tabela 1 - Número médio de brotações em cada coleta, realizadas em três épocas, a partir do corte raso para implantação do banco de estacas

Table 1 -Mean number of sprouts in each collection conducted in three periods, from shallow cut to minigarden clonal implantation

\begin{tabular}{cc}
\hline Época (semanas) & Média de Brotações \\
\hline 10 & 1,1 \\
18 & 4,5 \\
22 & 5,1 \\
\hline
\end{tabular}

Dados acumulativos, antes da coleta. Accumulative data, before cut.

Em minijardim de cedro-rosa (C. fissilis), Xavier et al. (2003) obtiveram 1,3 brotação por minicepa por mês, porém com manejoe avaliações diferentes desse experimento. Para híbridos de eucalipto (Eucalyptus urophylla $\mathrm{x} E$. grandis; E. grandis $\mathrm{x}$ Eucalyptus spp; E. tereticornis $\mathrm{x} E$. pellita), os dados de brotação por minicepa por mês foram de 1,7, segundo relatos de Wendling et al. (2000). Em espécies nativas, Santos (2002) utilizou sistemas de jardim miniclonal em tubetes plásticos de $200 \mathrm{~cm}^{3}$, com coletas de miniestacas, a cada 30 dias, obtendo produção mensal de 1,3 em cedro-rosa, 1,1 em mogno, 1,6 em angicovermelho e 3,8 em jequitibá-rosa.

Rosse (1995) observou não haver correlação entre o número de brotações e a porcentagem de enraizamento em clones de eucalipto.

São necessários estudos enfocando coletas seletivas de miniestacas em cedro-australiano, para conhecimento da produtividade contínua de miniestacas.

As primeiras brotações apresentaram altura superior à das brotações colhidas na segunda e terceira épocas (Figura 1). Entretanto, o diâmetro das brotações apresentaram diferente comportamento, com aumento no diâmetro das brotações no segundo corte e redução no terceiro (Figura 2).

Provavelmente, a diferença no comportamento das duas características, entre o primeiro e o segundo corte, refletiu o maior espaçamento dado às minicepas após a primeira coleta. A variação entre cortes deveu-se à diferença de intervalos entre as coletas.

\subsection{Miniestacas}

Houve $100 \%$ de enraizamento das miniestacas, independentemente da aplicação de AIB em três sucessivas coletas de miniestacas, provenientes do banco de estacas de origem seminal. O potencial de enraizamento foi favorecido pela utilização de material vegetativo proveniente da fase juvenil da planta.

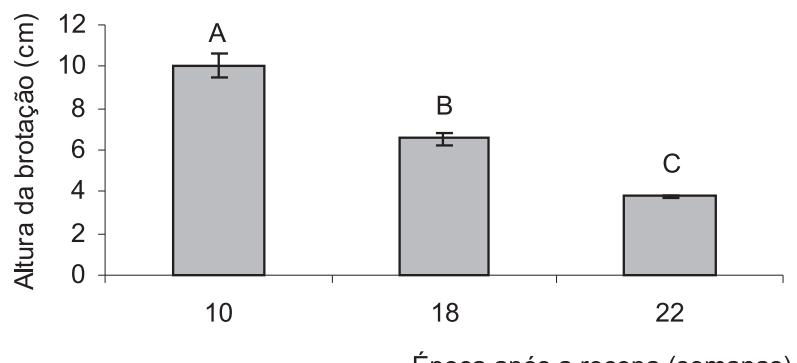

Barras representam o erro-padrão da média. CV (\%): 17,17. Bar represents the standard error of the mean value.

Figura 1 - Altura média das brotações de cedro-australiano colhidas em três épocas.

Figure 1 -Mean height of theAustralian Red Cedar sprouts harvested during three periods.

Os resultados de altura, diâmetro de colo, comprimento de raízes e diâmetro médio de raízes, aos 40 dias após o estaqueamento, são apresentados nas Figuras 3, 4, 5 e 6, respectivamente.

A altura das mudas, aos 40 dias, nas três épocas apresentou resultado semelhante ao das brotações nas épocas de coleta (Figuras 1 e 3 ). Isso comprova que miniestacas provenientes de brotos maiores geram mudas clonais com crescimento mais acelerado, com igual período de tempo de crescimento em casa de vegetação. Embora o tamanho das estacas tenha sido padronizado no momento da coleta, o maior intervalo entre as coletas permitiu maior acúmulo de reservas nas miniestacas utilizadas, acelerando, assim, o seu crescimento.

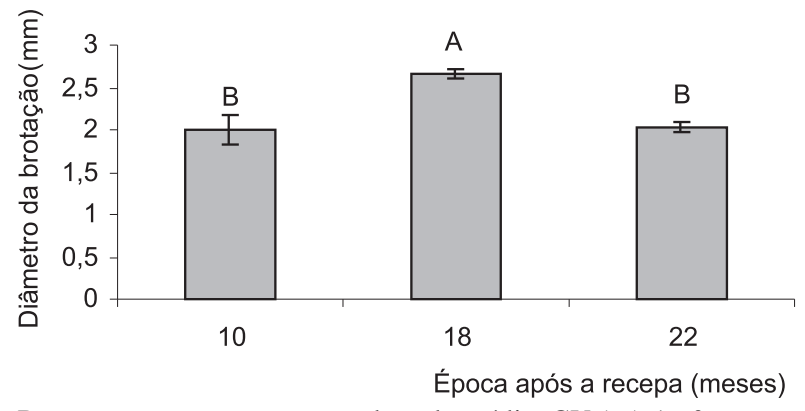

Barras representam o erro padrão da média. CV (\%):16,06. Bar represents the standard error of the mean value.

Figura 2 - Diâmetro médio das brotações de cedro australiano, colhidas em três s épocas.

Figure 2 - Diameter of the Australian Red Cedar sprouts harvested during three periods. 


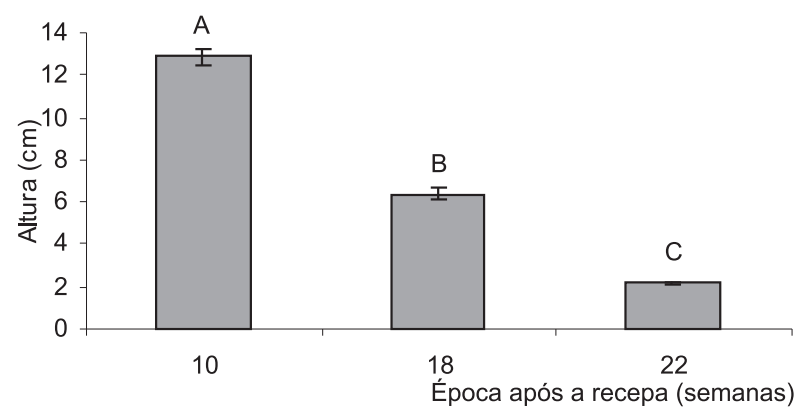

Barras representam o erro padrão da média. CV (\%):16,06. Bar represents the standard error of the mean value.

Figura 3 - Altura de mudas clonais de cedro-australiano, aos 40 dias após o estaqueamento, produzidas a partir de miniestacas, colhidas em três s épocas.

Figure 3-Height of the Australian Red Cedar clonal seedlings produced during three periods, measured 40 days after cutting establishment.

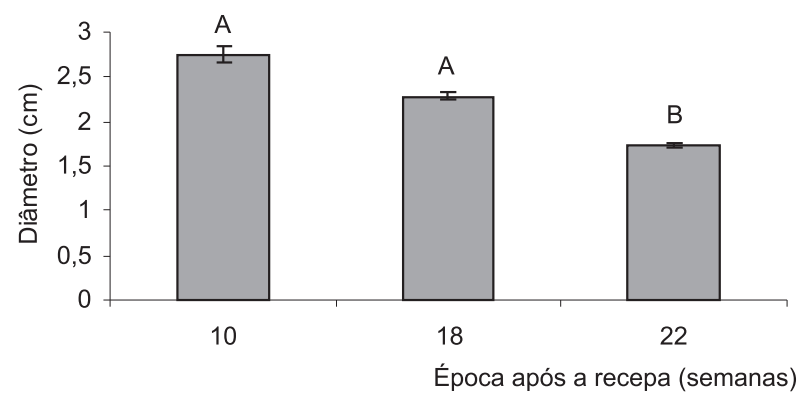

Barras representam o erro padrão da média. CV (\%):16,06. Bar represents the standard error of the mean value.

Figura 4 - Diâmetro de mudas clonais de cedro-australiano produzidas em três épocas, medido aos 40 dias após o estaqueamento.

Figure 4-Diameter of Australian Red Cedar clonal seedlings produced during three periods, measured 40 days after cutting establishment.

Segundo Paiva e Gomes (1995), estacas colhidas de uma mesma matriz e submetidas aos mesmos tratamentos respondem diferentemente quanto à taxa de enraizamento, em diferentes épocas do ano. Isso pode estar diretamente ligado ao teor de carboidratos armazenados na matriz. Quando maior o nível de reservas e maior a relação carbono/nitrogênio, maior o favorecimento do enraizamento das estacas.

Segundo Wendling et al. (2000), entre os fatores internos que influenciam o enraizamento está a espécie ou o clone, cujo potencial varia ainda com a época do ano, o que está diretamente ligado ao teor de carboidratos não estruturais. Esses autores encontraram variações entre clones de eucalipto no seu estudo de propagação clonal por miniestaquia. Rosse (1995), avaliando a capacidade de rebrota e enraizamento de estacas também em clones de eucalipto, observou que o diâmetro e altura dos brotos foram um dos fatores que afetam o enraizamento das estacas, como observado neste experimento.

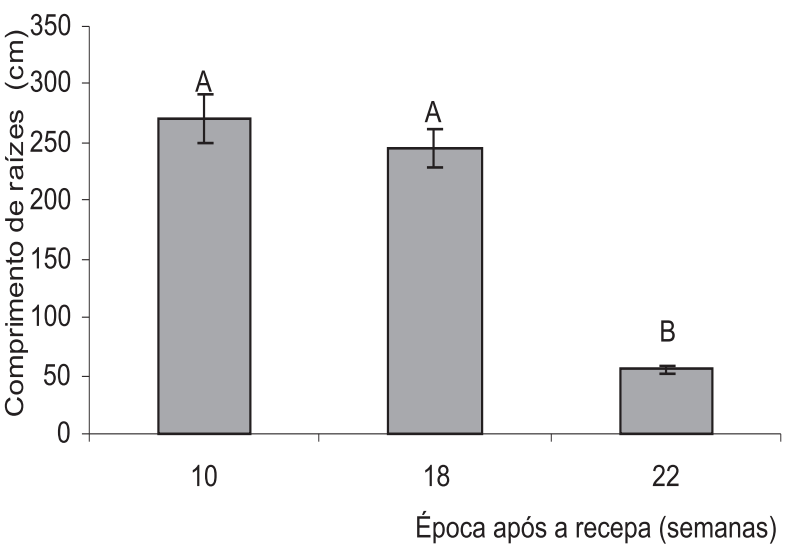

Barras representam o erro padrão da média. CV (\%):16,06. Bar represents the standard error of the mean value.

Figura 5-Comprimento de raízes de mudas clonais de cedroaustraliano produzidas em três épocas, medido aos 40 dias após o estaqueamento.

Figure 5 - Length of roots of Australian Red Cedar clonal seedlings produced during three periods, measured 40 days after cutting establishment.

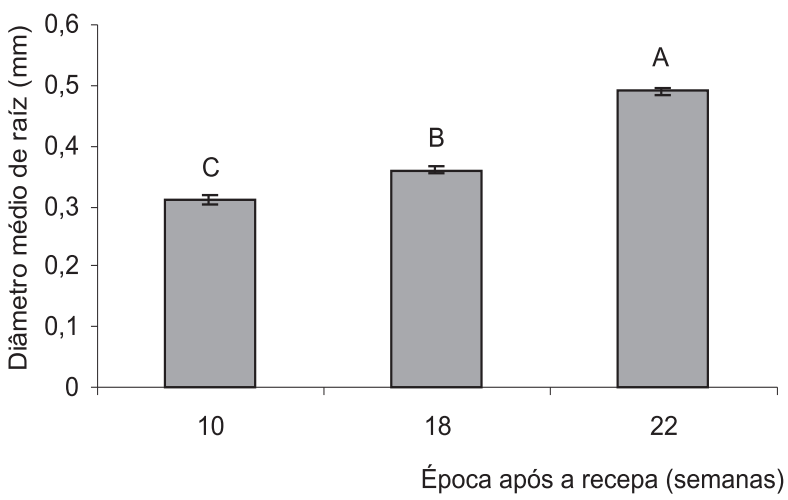

Barras representam o erro padrão da média. CV (\%):16,06. Bar represents the standard error of the mean value.

Figura 6-Diâmetro médio de raízes de miniestacas de cedroaustraliano produzidas em três épocas, medido aos 40 dias após o estaqueamento.

Figure 6-Mean diameter of Australian Red Cedar minicutting roots produced during three periods, measured 40 days after cutting establishment.

R. Árvore, Viçosa-MG, v.33, n.2, p.205-213, 2009 
Miller et al. (1982) comprovaram, em trabalho com estacas de Abies fraseri (Pursh) Poir, que o comprimento das estacas não afetou o percentual de enraizamento, porém estacas maiores apresentaram número maior de raízes, o que favorece a absorção de nutrientes e maior e mais acelerado crescimento das mudas clonais.

Conforme Paiva e Gomes (1995), as reservas parecem ser indispensáveis à sobrevivência do propágulo até o seu enraizamento e posterior desenvolvimento. As reservas em um nível conveniente não só facilitam a emissão de raízes e aumentam o aparato fotossintético, como também elevam a fotossíntese. Boa parte das reservas se transfere para a base da estaca, contribuindo para a formação dos primórdios radiculares.

O diâmetro das mudas e o comprimento das raízes não apresentaram diferenças entre o primeiro e o segundo corte (Figuras 4 e 5), mas tiveram maior crescimento que nas estacas produzidas na terceira coleta. Apesar de na primeira época de coleta as mudas apresentarem maior altura que na segunda, elas não diferiram em diâmetro entre as épocas 1 e 2, provavelmente pelo espaçamento entre as minicepas no viveiro, que foi aumentado a partir da primeira coleta, e pelo fato de o intervalo entre as coletas de 10 e 8 semanas não refletir em diferenças nas características do propágulo.

Embora com redução no comprimento, as raízes das mudas apresentaram aumento de diâmetros ao longo das três coletas (Figura 6). Estacas provenientes de brotações maiores estimularam a emissão de raízes mais compridas e mais finas, responsáveis pela absorção de água e nutrientes, permitindo, assim, o crescimento mais acelerado das mudas que aquelas provenientes de brotações menores.

O crescimento e enraizamento das mudas não foram influenciados pela aplicação de auxina, entretanto houve interação entre época e doses de AIB sobre a matéria seca da parte aérea ( Figura 7). A matéria seca da parte aérea foi maior na primeira coleta, sendo reduzida nas demais. O efeito da auxina ocorreu apenas nas miniestacas originadas da primeira coleta de miniestacas, provenientes de brotações mais robustas, apresentando comportamento quadrático, com ponto de máxima em $2.325 \mathrm{mg} \mathrm{L}^{-1}$ de AIB (Figura 7).

A variação da matéria seca observada na parte aérea das mudas em função das doses de AIB provavelmente se deveu ao número ou tamanho de folhas, uma vez que não houve a mesma influência sobre a altura e diâmetro das mudas. A auxina facilita o movimento de solutos para zonas de crescimento (CLELAND, 1995). Também Araújo et al. (2005) observaram efeito quadrático da aplicação de AIB em estacas de figueira (Ficus carica L.) sobre o número de folhas produzidas. Entretanto, verificaram o mesmo efeito na produção de raízes, o que não aconteceu nas mudas de cedro.

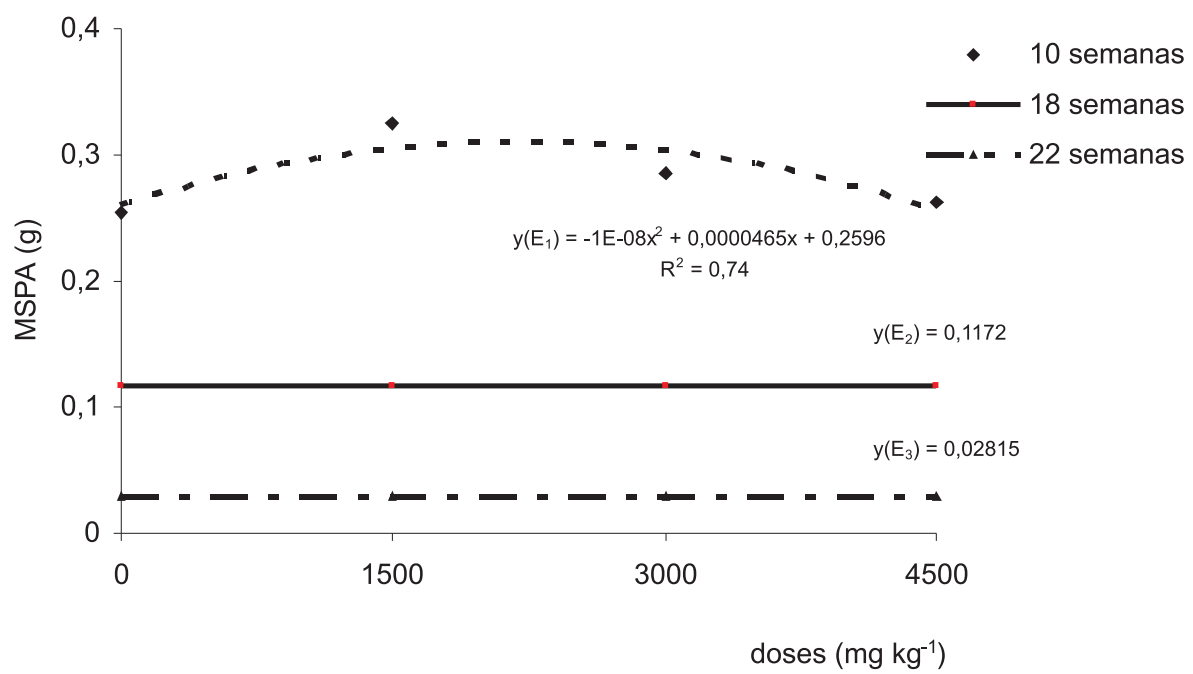

Figura 7 - Matéria seca da parte aérea de miniestacas de cedro-australiano em função da concentração de AIB e da época de colheita após a recepa, aos 40 dias após o estaqueamento.

Figure 7-Dry matter of the aerial part of Australian Red Cedar minicuttings, in function of AIB concentration and harvest time after cut, 40 days after the minicutting establishment. CV(\%): 17,16.

R. Árvore, Viçosa-MG, v.33, n.2, p.205-213, 2009 
Muitas espécies florestais necessitam do estímulo hormonal para induzir o enraizamento, como no caso de Eucalyptus grandis Hill ex Maiden. Titon et al. (2003), avaliando o efeito da aplicação de AIB (0, 1.000, 2.000 e $4.000 \mathrm{mg} \mathrm{L}^{-1}$ ) na sobrevivência, enraizamento e vigor de micro e miniestacas de quatro diferentes clones dessa espécie, observaram que, apesar de não haver efeito do regulador de crescimento sobre a altura e diâmetro do colo, tanto na microestaquia quanto na miniestaquia, dos quatro clones, houve aumento nos índices de enraizamento e de sobrevivência das miniestacas nas dosagens de 1.000 e $2.000 \mathrm{mg} \mathrm{L}^{-1}$, na maioria dos clones.

Pio et al. (2005), ao testarem o efeito de diferentes concentrações de AIB no enraizamento de estacas semilenhosas de oliveira (Olea europaea L.), observaram que o AIB apenas influenciou o sistema radicular. A concentração de $2.000 \mathrm{mg} \mathrm{L}^{-1}$ de AIB promoveu maior enraizamento, e a concentração de $3.000 \mathrm{mg} \mathrm{L}^{-1}$ de AIB em estacas com dois pares de folhas induziu melhores resultados em número de raízes por estacas e comprimento médio das raízes.

Como neste experimento, entretanto, algumas espécies ou clones não necessitaram de auxinas para o estímulo ao enraizamento de estacas e, ou, miniestacas. Wendling e Xavier (2005), estudando a influência do AIB e da miniestaquia seriada no enraizamento e vigor de miniestacas de alguns clones de Eucalyptus grandis Hill ex Maiden, também observaram que a aplicação de AIB, nas concentrações de 500, 1.500 e 3.000 mg $\mathrm{L}^{-1}$, não resultou no aumento do enraizamento e sobrevivência das miniestacas, nem no vigor geral das mudas. As diferentes concentrações de AIB (1.000, 2.000, 4.000 e $6.000 \mathrm{mg} \mathrm{L}^{-1}$ ) também não influenciaram o enraizamento das estacas apicais de jabuticabeira (Myrciaria jabuticaba), segundo estudos de Pereira et al. (2005). O mesmo resultado foi obtido por Pio et al. (2006) no enraizamento de estacas apicais de figueira (Ficus carica L) a 0 e $2.000 \mathrm{mg} \mathrm{L}^{-1}$ de AIB.

Pesquisas relacionadas ao enraizamento de espécies florestais apontaram as diferentes capacidades de enraizamento das espécies e de clones de uma mesma espécie. Goulart (2003) observou não haver viabilidade de propagação vegetativa de candeia (Eremanthus erythropappus (DC.) Macleish), devido ao baixo enraizamento, independentemente da utilização de reguladores de crescimento. Wendling (1999) comprovou variação no percentual de enraizamento em diferentes clones de híbridos de Eucalyptus spp. por miniestaquia, e Xavier et al. (2003) comprovaram o elevado potencial de enraizamento de miniestacas caulinares de cedro rosa a partir de material de origem seminal. Wendling e Souza Junior (2007) observaram, ao implementarem e adequarem a técnica de miniestaquia à cultura da erva-mate (Ilex paraguariensis St.Hil.), com miniestacas submetidas a diferentes dosagens de AIB (0, 1.500, 3.000 e $6.000 \mathrm{mg} \mathrm{L}-1$ ), que a miniestaquia dessa planta, a partir de material de origem seminal, é tecnicamente viável, atingindo-se valores médios de $75 \%$ de sobrevivência aos 120 dias de idade das mudas, sem a necessidade de aplicação de reguladores de crescimento para enraizamento.

\section{CONCLUSÕES}

Considerando as condições em que o experimento foi conduzido, conclui-se que é viável a propagação do cedro-australiano por enraizamento de miniestacas provenientes de minicepas de origem seminal, sem a necessidade da aplicação de auxina.

As minicepas apresentaram $100 \%$ de sobrevivência, com tolerância a coletas sucessivas de miniestacas.

Miniestacas provenientes de brotações maiores originaram mudas com potencial de crescimento mais acelerado.

\section{REFERÊNCIAS}

ASSOCIAÇÃO BRASILEIRA DOS PRODUTORES DE FLORESTAS PLANTADAS - ABRAF. Anuário Estatístico da ABRAF. Ano base: 2005. Brasília: 2006. 80p.

Alfenas, A. C. et al. Clonagem e doenças do eucalipto. Viçosa, MG: Universidade Federal de Viçosa, 2004. 442p.

ARAUJO, J. P. C. et al. Propagação da figueira por estaquia tratadas com AIB. Bioscience Journal, v.21, n.2, p.59-63, 2005.

CASTRO-GAMBOA, I. Estudo fitoquímico da raiz de Toona ciliata e do cavalo do enxerto de Toona ciliata/Cedrela odorata: uma contribuição à quimiossistemática e à ecologia na interação Hypsipyla-Meliaceae. 2000. 212f. Tese (Doutorado em Química) - Universidade Federal de São Carlos, São Carlos, 2000.

R. Árvore, Viçosa-MG, v.33, n.2, p.205-213, 2009 
CLELAND, R. E. Auxin and cell elongation. In: DAVIES, P. J. Plant hormones: physiology, biochemistry and molecular biology. 2.ed. New York: 1995. p.214-227.

CUNNINGHAM, S. A. et al. Patterns of host use by the shoot-borer Hypsipyla robusta (Pyralidae: Lepidoptera) comparing five Meliaceae tree species in Asia and Australia. Forest Ecology and Management, v.205, p.351-357, 2005.

FREITAS, T. A. S. et al. Desempenho radicular de mudas de eucalipto produzidas em diferentes recipientes e substratos. Revista Árvore, v.29, n.6, p.853-861, 2005.

GOULART, P. B. Desenvolvimento de metodologia para enraizamento de estacas de candeia (Eremanthus erythropappus (DC) MacLeish). Lavras: Universidade Federal de Lavras, 2003. 32p.

HIGASHI, E. N.; SILVEIRA, R. L. V.A.; GONÇALVES, A. N. Propagação vegetativa de eucalyptus: princípios básicos e a sua evolução no Brasil.

Piracicaba: IPEF, 2000. 11p. (Circular Técnica, 192).

LORENZI, H. et al. Árvores Exóticas no Brasil: madeireiras, ornamentais e aromáticas. Nova Odessa: Instituto Plantarum, 2003. 385p.

MILLER, N. F.; HINESLEY, L. E.; BLAZICH, F. A. Propagation of fraser fir stem cuttings: effects of type of cuttimg, length of cutting, and genotype. HortScienc, v.17, n.5, p.827-829, 1982.

OIANO, J. N. Estudo Fitoquímico da Toona ciliata: Uma contribuição à quimiossistemática do gênero e a ecologia da interação Hypsipyla-Meliaceae. 2000. 287f. Tese (Doutorado em Química), São Carlos, Universidade Federal de São Carlos, São Carlos, 2000.

PAIVA, H. N.; GOMES, J. M. Propagação vegetativa de espécies florestais. Viçosa, MG: Universidade Federal de Viçosa, 1995. 40p.

PEREIRA, M. et al. Efeitos de substratos, valores de ph, concentrações de AIB no enraizamento de estacas apicais de jabuticabeira [Myrciaria jabuticaba (Vell.) $\mathrm{O}$. Berg.] Scientia Forestalis, n.69, p.84-92, 2005.

PIMENTEL-GOMES, F.; GARCIA, C. H. Estatística aplicada a experimentos agronômicos e florestais: exposição com exemplo e orientações para uso de aplicativos. Piracicaba: FEALQ, 2002. 309p.
PINHEIRO, A. L.; LANI, L. L.; COUTO, L. Cultura do cedro australiano para produção de madeira serrada. Viçosa, MG: Universidade Federal de Viçosa, 2003. 42p.

PIO, R. et al. Enraizamento de diferentes tipos de estacas de oliveira (Olea europaea 1.) utilizando ácido indolbutírico Ciência e

Agrotecnologia, v.29, n.3, p.562-567, 2005.

PIO, R. et al. Propagação de estacas apicais de figueira: diferentes ambientes, ácido indolbutírico e tipo de estaca. Ciência e Agrotecnologia, v.30, n.5, p.1021-1026, 2006.

ROSSE, L. N. Estimativas de parâmetros genéticos e fenotípicos da capacidade de rebrotamento e do enraizamento de estacas em clones de Eucalyptus spp. 1995. 77f. Dissertação (Mestrado em Genética e Melhoramento de Plantas) - Universidade Federal de Lavras, Lavras, 1995

SAntos, G. A. Propagação vegetativa de mogno, cedro rosa, jequitibá rosa e angico vermelho por miniestaquia. Viçosa, MG: Universidade Federal de Viçosa, 2002. 75p.

SCOCCHI, A. et al. Conservación de semillas de cedro australiano (Toona ciliata). Plant

Genetic Resources Newsletter, n.137, p.22-25, 2006.

TEIXEIRA, D. A. Promoção de enraizamento $e$ indução de resistência sistêmica à ferrugem (Puccinia psidii) e à mancha de Cylindrocladium candelabrum mediadas por rizobactérias em Eucalyptus spp. 2001. 67f. Tese (Doutorado em Fitopatologia) Universidade Federal de Viçosa, Viçosa, 2001.

TITON, M.; XAVIER, A.; OTONI, W. C. Dinâmica do enraizamento de microestacas e miniestacas de clones de Eucalyptus grandis. Revista Árvore, v.26, n.6, p.665-673, 2002.

TITON, M. et al. Efeito do AIB no enraizamento de miniestacas e microestacas de clones de Eucalyptus grandis W. Hill ex Maiden. Revista Árvore, v.27, n.1, p.1-7, 2003. 
WEndling, I. Propagação clonal de híbridos de Eucalyptus spp. por miniestaquia. 1999. 70f. Dissertação (Mestrado em Ciência Florestal) - Universidade Federal de Lavras, Lavras, 1999.

WENDLING, I.; SOUZA JUNIOR, L. Propagação vegetativa de erva-mate (Ilex paraguariensis Saint Hilaire) por miniestaquia de material juvenil. In: http://floraefauna.com/artigos/ propagacao_vegetativa_de_erva_mate.htm em 02/ 08/2007 página mantida pela Flora e Fauna.
WENDLING, I.; XAVIER, A. Influência do ácido indolbutírico e da miniestaquia seriada no enraizamento e vigor de miniestacas de clones de Eucalyptus grandis. Revista Árvore, v.29, n.6, p.921-930, 2005.

WENDLING, I. et al. Propagação clonal de híbridos de Eucalyptus spp. por miniestaquia. Revista Árvore, v.24, n.1, p.181-186, 2000.

XAVIER, A. et al. Propagação vegetativa de cedro-rosa por miniestaquia. Revista Árvore, v.27, n.2, p.139-143, 2003. 